\title{
TESES SOBRE O CONCEITO DE CRÍTICA
}

THESES ON THE CONCEPT OF CRITICISM

\author{
Nabil Araújo \\ ORCID 0000-0001-6352-2437
}

Universidade do Estado do Rio de Janeiro

Rio de Janeiro, RJ, Brasil

\section{Resumo}

Neste texto, apresentamos algumas teses sobre o conceito de crítica, concernentes à sua inevitabilidade, à sua natureza judicativa, à diferença entre modernidade crítica e sistema crítico clássico, ao julgamento inaugural e sua relação com a democracia, ao ensino de literatura como ensino de crítica literária.

Palavras-chave: Crítica, modernidade crítica, julgamento inaugural, democracia, ensino de literatura.

\begin{abstract}
In this text, we will present some theses on the concept of criticism, concerning its inevitability, its judicative nature, the difference between Critical Modernity and Classical Critical System, fresh judgement and its relationship with democracy, teaching of literature as teaching of literary criticism.
\end{abstract}

Keywords: Criticism, Critical Modernity, fresh judgement, democracy, teaching of literature.

\section{Résumé}

Dans ce texte, nous présentons quelques thèses sur le concept de critique, concernantes à sa inevitabilité, sa nature judicative, à la différence entre modernité critique et le système critique classique, au jugement inaugural e sa relation avec la démocratie, au enseignement de littérature comme enseignement de critique littéraire.

Mots-clés: Critique, modernité critique, jugement inaugural, démocratie, enseignement de littérature. 
Neste momento tumultuoso, em que a celeridade das mudanças vem sufocando a reflexão e o diálogo, mais que nunca é imperativo investir nas funçóes judiciosas, corretivas e orientadoras da crítica (SEVCENKO, 2001, p. 19).

\section{I - A crítica é inevitável}

[...] we might remind criticism is as inevitable as breathing, and that we should be none the worse [...] for criticizing our own minds in their work of criticism (T. S. Eliot, "Tradition and individual talent", 1919) ${ }^{1}$

A crítica é tão inevitável quanto respirar, sentencia Eliot; de fato, parece improvável passarmos um dia sequer no qual, seja por palavras a outrem, ou a nós mesmos, não sejamos críticos, sob algum aspecto, a propósito de algo que vemos ou ouvimos, que lemos ou assistimos. "Quando quer que haja alguma espécie reconhecível de objeto ou evento, e terreno para se ter interesse em coisas dessa espécie, somos confrontados com a necessidade de avaliar e estimar", lembra, com efeito, Monroe Beardsley (1981, p. 153), acrescentando: "E poemas não são, neste sentido altamente abstrato, diferentes de refrigeradores, senadores, emendas constitucionais, jogadores de tênis, corporaçóes e gatos" (BEARDSLEY, 1981, p. 153).

A crítica em geral revela-se, assim, "um modo de discurso que é pervasivo em nossas atividades sérias e essencial à racionalidade na conduta da vida", na medida em que "viver de um modo integralmente humano envolve tentar fazer escolhas racionais, isto é, escolher por boas razóes", algo que "demanda julgamento do que é melhor ou pior em certo campo de alternativas e entendimento do que faz uma coisa melhor ou pior do que outra” (BEARDSLEY, 1981, p. 152-153).

A inevitabilidade da crítica na vida cotidiana não nos deveria impedir, antes pelo contrário, de tentar criticar nossas próprias mentes em seu trabalho de crítica... crítica da crítica: em que deve consistir, afinal, o "trabalho de criticar"?

1 "[...] poderíamos lembrar que a crítica é tão inevitável quanto respirar, e que não deveríamos estar de modo algum em piores condiçôes [...] por criticarmos nossas próprias mentes em seu trabalho de crítica" (ELIOT, 1975, p. 37). Esta e as demais traduçôes de trechos em língua estrangeira aqui citados sấo de minha autoria. 
O termo kritikós - a partir do grego antigo krités, "juiz", e krineín, "julgar" - foi usado para designar "juiz de literatura" já no século IV a.C., passando para o latim como criticus (cf. WELLEK, 1963). Como todo krités, é de se esperar que também o kritikós julgue a partir de kritérion. Se compreendermos, por este termo, "os fundamentos relativos aos valores mais elevados de uma sociedade, em nome e em função dos quais os juízos e as críticas são feitos, os julgamentos são conduzidos e as decisôes são tomadas" (SEVCENKO, 2001, p. 19), precisamos distinguir, quanto a isso, a crítica na Antiguidade, na qual o valor estético náo se dissociava do valor moral nem do cognitivo (pense-se na mímesis e na verossimilhança aristotélicas), da crítica na Modernidade, caracterizada justamente pelo que Max Weber descreveu como a diferenciação e a autonomizaçáo das esferas de valor cognitivo, moral e estético.

\section{III - Modernidade crítica}

Se coube a Immanuel Kant, em sua terceira Crítica - a da "faculdade de julgar": Kritik der Urteilskraft (1790) -, a mais bem acabada e a mais influente formulação teórica da autonomia da esfera estética em face da cognitiva e da moral, coube também a ele, e no mesmo gesto, a identificação do juízo de gosto com o "juízo reflexivo", o qual se dá justamente na ausência de qualquer kritérion a priori (em contraposição ao "juízo determinante", no qual o kritérion está dado a priori), um julgamento, pois, carente de princípio ou fundamento, de modo a instaurar o que se pode chamar de modernidade crítica:

aquela conjuntura na qual o crítico estético-literário tem reservados a si, e como nunca antes, um domínio e uma jurisdição que lhe seriam próprios e exclusivos, ao mesmo tempo que se vê privado do fundamento necessário à tomada de posse do referido domínio e ao exercício legítimo da referida jurisdição - fundamento esse que, portanto, deve ser doravante buscado, conquistado pelo crítico, e por ele estabelecido, finalmente, de maneira consensual. (ARAÚJO, 2016, p. 209).

Essa busca pelo fundamento autoinstituidor e autolegitimador da crítica de arte e literatura traduziu-se numa progressiva emergência de pretensas respostas à subjetivação radical da estética no âmbito da modernidade póskantiana: respostas que se revelam possíveis mas não compossiveis à busca pelo kritérion estético, isto é, elas não são, como respostas, concomitantemente possíveis, mas mutuamente excludentes, e isso em sua origem mesma: a própria 
emergência de uma delas como resposta implica justamente a negação das demais como respostas. "Qualquer uma delas, pois, que emerja dessa disputa como 'a' resposta há de permanecer assombrada por aquela incompossível possibilidade outra que tivera de negar e recalcar para se instituir e se legitimar como resposta." (ARAÚJO, 2016, p. 209).

Na medida mesma em que essas possibilidades de respostas incompossiveis se prenunciam agonisticamente no horizonte crítico contemporâneo, necessário se faz redefinir, contemporaneamente, a própria natureza do julgamento implicado pela crítica estética.

IV - Crítica é julgamento inaugural

Le concept de critique, en tant qu'il implique la décision sous la forme de jugement et la question au sujet du droit de juger, a ainsi un rapport essentiel, en lui-même, à la sphère du droit (Jacques Derrida, Force de loi: le fondement mystique de l'autorité, 1994). ${ }^{2}$

O conceito de crítica implica a decisão sob a forma de julgamento (bem como a questáo a respeito do direito de julgar) - e, nessa medida, guarda uma relação essencial com a esfera do direito. Derrida recupera aí o laço fundamental, desfeito em Kant, entre o kritikós e o krités, ambos voltados, afinal, para a krinein à luz de kritérion.

Se só pode julgar seguindo uma regra de direito ou uma lei geral, um juiz [krités/ kritikós] deve, não obstante, "assumi-la, aprová-la, confirmar seu valor, por um ato de interpretação reinstaurador, como se, no limite, a lei não existisse anteriormente, como se o juiz a inventasse ele mesmo em cada caso" (DERRIDA, 1994, p. 50-51). Este "julgamento inaugural" deve, pois, "ser conforme a uma lei preexistente, mas a interpretação reinstauradora, reinventiva e livremente decisória do juiz responsável requer que sua 'justiça’ não consista somente na conformidade, na atividade conservadora e reprodutiva do julgamento" (DERRIDA, 1994, p. 51). Se não se confunde, pois, com o juízo determinante, no qual "se aplica tranquilamente uma boa regra a um caso particular, a um exemplo corretamente subsumido" (DERRIDA, 1994, p. 38), o julgamento que Derrida entáo denomina inaugural também não se confundiria com o juízo reflexivo, posto que, nele, tudo se passa apenas como se a lei não existisse anteriormente, como se o juiz a inventasse ele mesmo em cada caso, e náo, de fato, numa ausência efetiva e absoluta de toda e qualquer

2 "O conceito de crítica, na medida em que implica a decisão sob a forma de julgamento e a questáo a respeito do direito de julgar, tem assim uma relaçáo essencial, em si mesmo, com a esfera do direito." (DERRIDA, 1994, p. 80). 
lei ou regra, já que ele "deve ser conforme a uma lei preexistente", já que, nele, a decisão "deve seguir uma regra de direito ou uma lei geral".

Aqui se faz necessário retomar o que Derrida afirma acerca do indecidível como a urgência mesma de uma decisão impossível a partir "[d]a oscilação ou [d] a tensão entre duas decisôes"; a partir "[d] a oscilação entre duas significaçôes ou duas regras contraditórias e muito determinadas, mas igualmente imperativas" (DERRIDA, 1994, p. 53). Ora, trata-se, aí, como se vê, não de uma ausência absoluta de regras (juízo reflexivo), e sim, ao contrário, de uma potencial abundância delas; na medida, contudo, em que as regras em questão seriam igualmente imperativas, e, a um só tempo, contraditórias entre si, elas se apresentam, no momento do julgamento, como igualmente possíveis, mas não compossivveis, isto é, não possíveis ao mesmo tempo. Daí que uma decisão seja requerida não apenas em face do objeto do julgamento ("bom" ou "mau", "culpado" ou "inocente" etc.), mas também, e concomitantemente, em relação à própria regra que permitiria, enfim, o julgamento do referido objeto como "isto" ou "aquilo". Daí que a regra emerja, em cada caso, como o efeito de uma decisão impossível - em contraste com a mera aplicação de uma regra a priori a um caso particular -, decisão esta que, ao largo da pretensa "tranquilidade" que acompanha o juízo determinante, permanecerá, como tal, assombrada pelo indecidível.

Projeta-se no horizonte crítico contemporâneo a mesma oscilação entre regras contraditórias e muito determinadas, mas igualmente imperativas, que Derrida divisa quando trata do indecidível, mas também a mesma urgência de uma decisão impossível em face dessa oscilação, a mesma urgência, em suma, de um julgamento inaugural, na forma de uma dupla decisão no indecidível, sem o qual, na verdade, não há verdadeiro ato crítico:

a decisão em jogo no ato crítico diz respeito náo apenas ao juízo de gosto perante a obra lida, mas também, e de um só golpe, ao princípio teórico à luz do qual o referido juízo de gosto se faz possível - princípio teórico esse que, por isso mesmo, não se encontra, em nenhuma medida, dado a priori e pronto para ser aplicado, mas que deve ser obtido no próprio ato crítico, o que se quer, entáo, chamar de ato crítico confundindo-se, na verdade, em larga medida, com essa obtenção de princípio. Essa obtenção - enfatize-se - traduz-se numa determinada escolha, numa determinada decisão, aquela entre possibilidades diversas e divergentes de princípios teóricos para o juízo de gosto inerente à prática crítica, uma decisão em ato, pois, para a qual, bem entendido, não há nem pode haver nenhuma garantia externa ao próprio ato crítico como ato de escolha, dupla (ARAÚJO, 2017, p. 50). 


\section{V - Dissenso, democracia e crítica}

This is why an approach like deconstruction, which reveals the impossibility of establishing a consensus without exclusion is of fundamental importance for grasping what is at stake in democratic politics. Because it warns us against the illusion that Justice could ever be instantiated in the institutions of any society, deconstruction forces us to keep the democratic contestation alive. [...] As Derrida stresses, without taking a rigorous account of undecidability, it is impossible to think the concepts of political decision and ethical responsibility. (Chantal Mouffe, "Deconstruction, Pragmatism and Democracy", 1996).

A concepção derridiana de julgamento inaugural como performance aporética de uma decisão no indecidível evidencia aquilo "que está em jogo na política democrática" segundo Chantal Mouffe. "Como condições de possibilidade para a existência de uma democracia pluralista, conflitos e antagonismos constituem ao mesmo tempo a condição de impossibilidade de sua realização final. Este é o 'double bind que a desconstrução desvela", reconhece Mouffe, e conclui: "É por isso que, nas palavras de Derrida, a democracia estará sempre 'por vir', atravessada pela indecidibilidade e para sempre mantendo aberto seu elemento de promessa” (MOUFFE, 1996, p. 11).

Como "uma nova forma política de sociedade", a democracia liberal "consiste na legitimação do conflito e na recusa a eliminá-lo através da imposição de uma ordem autoritária", instituindo-se, assim, essencialmente como "uma democracia pluralista", observa Mouffe, arrematando: "Sua novidade consiste em sua previsão da diversidade de concepçóes do bem, não como algo negativo que deveria ser suprimido, mas como algo a ser valorizado e celebrado" (MOUFFE, 1996, p. 8). Daí a necessidade de um suporte institucional à práxis democrática:

Isto requer a presença de instituiçóes que estabeleçam uma dinâmica específica entre consenso e dissenso. Consenso, claro, é necessário, mas deveria ser limitado às instituiçôes que são constitutivas da ordem democrática. Uma democracia pluralista precisa também dar espaço à expressão do dissenso e a interesses e valores conflitantes. E estes não deveriam ser vistos como obstáculos temporários no caminho para o consenso, uma vez que, na sua ausência, a democracia deixaria de ser pluralista. (MOUFFE, 1996, p. 8).

3 "É por isso que uma abordagem como a desconstrução, que revela a impossibilidade de se estabelecer um consenso sem exclusão, é de fundamental importância para apreender o que está em jogo na política democrática. Porque nos previne contra a ilusâo de que a Justiça poderia sempre ser instanciada nas instituiçôes de qualquer sociedade, a desconstrução nos obriga a manter viva a contestação democrática. [...] Como Derrida enfatiza, sem levar em rigorosa conta a indecidibilidade, é impossível pensar os conceitos de decisão política e de responsabilidade ética." (MOUFFE, 1996, p. 9-10). 
Caberia às instituiçóes constitutivas da ordem democrática, em suma, promover, através desta "dinâmica específica entre consenso e dissenso", o apreço pluralista pelo conflito de interesses e valores, lembrando que "apreender a natureza da política democrática requer um entrar em acordo com a dimensão de antagonismo que está presente nas relaçóes sociais (MOUFFE, 1996, p. 8). Por sua vez, angariar a adesão dos indivíduos a tais instituiçôes e ao que elas promovem torna-se o grande desafio de uma educação para a democracia na contemporaneidade:

É particularmente importante na conjuntura atual, caracterizada, como tal, por uma crescente desafeiçáo pela democracia, compreender como uma forte adesão aos valores e instituiçóes democráticos pode ser estabelecida, e que o racionalismo constitui um obstáculo a tal compreensão. É necessário perceber que não é oferecendo argumentos racionais sofisticados, nem fazendo reivindicaçóes de verdade contextualmente-transcendentes sobre a superioridade da democracia liberal, que valores democráticos podem ser nutridos. A criação de formas democráticas de individualidade é uma questão de identificação com valores democráticos, e este é um processo complexo que tem lugar através de uma diversidade de práticas, discursos e jogos de linguagem. (MOUFFE, 1996, p. 5).

Como julgamento inaugural, dupla decisão no indecidivel, julgamento atravessado, enquanto performance aporética, justamente pela indecidibilidade à luz da qual se torna possível pensar os conceitos de decisão política e de responsabilidade ética, o ato crítico apresenta-se como uma das práticas, discursos e jogos de linguagem capazes de proporcionar, sobretudo na atual conjuntura de desafeição pela democracia, aquela identificação com valores democráticos que, segundo Mouffe, se encontra na base da criaçáo de formas democráticas de individualidade. Daí a urgência de uma nova pedagogia estética, voltada para o desenvolvimento de uma competência crítica aporética a serviço do debate ético-político numa esfera pública democrática.

\section{VI - A crítica é o que se ensina (quando se diz ensinar literatura)}

$[\ldots]$ at no point is there any direct learning of literature itself. Physics is an organized body of knowledge about nature, and a student of it says that he is learning physics, not nature. Art, like nature, has to be distinguished from the systematic study of it, which is criticism. It is therefore impossible to "learn literature": one learns about it in a certain way, but what one learns, transitively, is the criticism of literature. Similarly, the difficulty often felt in "teaching literature" arises from the fact that it cannot be done: the criticism of literature is all that can be directly taught. Literature is not a subject of 
study, but an object of study: the fact that it consists of words, as we have seen, makes us confuse it with the talking verbal disciplines. The libraries reflect our confusion by cataloguing criticism as one of the subdivisions of literature. (Northrop Frye, Anatomy of Criticism, 1957). ${ }^{4}$

Tomar a crítica como uma subdivisão da literatura implica, para Northrop Frye, compactuar com "a teoria do parasita", isto é, com a concepçáo da crítica como "uma forma parasitária de expressão literária, uma arte baseada numa arte preexistente, uma imitação de segunda mão do poder criativo" e do crítico como "um parasita ou artista manque", a qual, alertava Frye (2000, p. 3), "ainda é muito popular, especialmente entre os artistas", eventualmente "reforçada por uma analogia dúbia entre as funçóes criativa e procriadora, de modo que ouvimos falar assim da 'impotência' e da 'esterilidade' do crítico, de sua aversão a pessoas genuinamente criativas, e assim por diante"; e se a "idade de ouro da crítica anticrítica foi a parte final do século XIX", conclui Frye (2000, p. 3), "alguns de seus preconceitos ainda estão por aî".

Estão, sem dúvida, estendendo-se até hoje, seria preciso reconhecer: a retórica anticrítica há muito ultrapassou o círculo dos artistas para se imiscuir na própria crítica acadêmica, como atesta a recente institucionalizaçáo de um slogan criptomoderno como "pós-crítica". Não se trata aqui de rastrear o ritornello dos preconceitos anticríticos da crítica acadêmica até hoje, nem mesmo o do preconceito invertido da valorização do caráter "literário" (e náo judicativo) de uma crítica autoproclamada "pós-crítica". O diagnóstico quanto a isso foi contundentemente enunciado pelo próprio Frye:

Um público que tenta prescindir da crítica, e afirma que sabe o que quer ou do que gosta, brutaliza as artes e perde sua memória cultural. Arte pela arte é um abandono da crítica que redunda num empobrecimento da própria vida civilizada. O único modo de se antecipar ao trabalho da crítica é por meio

4 “"...] em nenhum aspecto há qualquer aprendizado direto da literatura ela mesma. A física é um corpo organizado de conhecimento sobre a natureza, e quem a estuda diz que está aprendendo física, não natureza. A arte, como a natureza, tem que ser distinguida do estudo sistemático dela, que é a crítica. É, pois, impossível 'aprender literatura’: aprende-se sobre ela em certa medida, mas o que se aprende, transitivamente, é a crítica de literatura. De modo semelhante, a dificuldade frequentemente sentida em 'ensinar literatura' emerge do fato de que isso náo pode ser feito: a crítica da literatura é tudo o que pode ser diretamente ensinado. A literatura não é uma área de estudo, mas um objeto de estudo: o fato de que ela consiste de palavras, como temos visto, faz com que a confundamos com as disciplinas verbais de fala. As bibliotecas refletem nossa confusão ao catalogar a crítica como uma das subdivisōes da literatura" (FRYE, 2000, p. 11-12). 
da censura, que tem a mesma relação com a crítica que o linchamento tem com a justiça. (FRYE, 2000, p. 4).

A aproximação da crítica com a justiça se faz aqui, novamente, bastante oportuna: pois se para que haja justiça, no sentido pleno do termo, náo basta que se evite o linchamento, também para que haja crítica, no sentido pleno do termo, não basta que se evite a censura. E se o que se ensina, quando se diz ensinar literatura, é mesmo a crítica, é preciso admitir que se trata, no caso de nossa educação literária historicista e nacionalista de nível médio e superior, de um ensino antidemocrático de crítica.

Uma história literária arquitetada e difundida de modo a antes ocultar do que explicitar as premissas em que se baseia para valorizar determinadas obras em detrimento de outras náo pode proporcionar ao aluno a possibilidade de desenvolver as competências e habilidades que lhe permitam emitir um verdadeiro juízo crítico sobre os autores e obras com que trava contato, já que o próprio modo pelo qual os autores e obras em questấo são entáo apresentados e estudados pressupóe que o juízo crítico acerca dos mesmos já tenha sido formulado, e de maneira peremptória: tal como no campo religioso, a canonização (de autores e obras), também aí, implica uma instância ativa (o sujeito da canonização), circunscrita a um restritíssimo círculo de autoridade, e uma instância passiva (os beneficiários do cânone), extensiva a todos aqueles a quem cabe submeter-se às decisôes da autoridade canonizadora, reproduzindo acriticamente seus posicionamentos.

Se o estudo e o ensino de literatura parecem já não ter a relevância acadêmica e social de outrora, isso deve ser compreendido no âmbito de uma crise mais ampla, dita "da Cultura", sobretudo no que esta se encontra intrinsecamente relacionada à dita crise "da Universidade". No hoje clássico The University in Ruins (1996), Bill Readings diagnosticava o problema nos termos, ainda mais amplos, de um "declínio do Estado-Naçáo": na medida em que a Cultura, em sua acepção moderna, como identidadelunidade de saberes e como Bildung (desenvolvimento e cultivo do caráter), justifica-se, em última instância, em função do projeto moderno de Estado-Nação, viabilizado pela Universidade como produtora, protetora e inculcadora de uma ideia de cultura nacional; e na medida em que o Estado-Nação claramente deixa de ser a unidade elementar do capitalismo global contemporâneo, o que assistimos é o declínio da própria missão cultural nacional que até agora havia sido a razão de ser da Universidade, sobretudo das Humanidades, e, em especial, dos Estudos Literários ( $c f$. READINGS, 1996). Apesar disso, o estudo e o ensino de literatura em nossas universidades e escolas continuam primariamente fundamentados no critério da nacionalidade, quando não deliberadamente orientados por uma ultrapassada ideologia nacionalista. 
O modelo oitocentista de ensino de literatura pela via das histórias literárias nacionais não apenas perdeu sua razão político-ideológica de ser, como claramente não corresponde (na verdade, nunca correspondeu) à demanda pedagógica pelo desenvolvimento da competência crítica dos alunos - e isto por uma razão muito simples, apesar de bastante grave: quando se centraliza a prática escolar de leitura e apreciação literária numa lista restrita de autores e obras previamente estabelecida (o chamado cânone literário nacional), o aluno limita-se a absorver o produto de uma escolha feita por terceiros, sem que seja levado a refletir sobre os critérios e procedimentos que presidiram tal escolha e, o que é pior, sem que se torne capaz de justificar suas próprias escolhas estético-literárias.

Buscar desenvolver a competência crítica dos alunos no trato com textos literários é a tarefa primordial de uma formação estética para os novos tempos (democráticos).

\section{VII - A crítica sob o vírus do iliberalismo}

Democratically elected regimes, often ones that have been reelected or reaffirmed through referenda, are routinely ignoring constitutional limits on their power and depriving their citizens of basic rights and freedoms. (Fareed Zakaria, "The rise of illiberal democracy", 1997). ${ }^{5}$

Em 1997, Fareed Zakaria identificou "a ascensão de um fenômeno perturbador na vida internacional - a democracia iliberal” (ZAKARIA, 1997, p. 22), perturbador ainda que minoritário, pois o cientista político não tinha dúvidas: "Vivemos numa era democrática" (ZAKARIA, 1997, p. 42). Se o preocupante diagnóstico se restringia, então, a um espectro de países quase que exclusivamente não ocidentais, "do Peru à Autoridade Palestina, de Serra Leoa à Eslováquia, do Paquistão às Filipinas" (ZAKARIA, 1997, p. 22), caberia, segundo o autor, à comunidade ocidental, protagonizada pelos Estados Unidos, o combate à difusão global do novo "vírus", impedindo-se, com isso, uma possível pandemia:

Hoje, em face de um proliferante vírus do iliberalismo, o papel mais útil que a comunidade internacional, e mais importantemente os Estados Unidos, pode desempenhar é consolidar a democracia onde ela criou raiz e encorajar o desenvolvimento gradual do liberalismo constitucional ao redor do globo. Democracia sem liberalismo constitucional é não somente inadequada, mas

5 "Regimes democraticamente eleitos, frequentemente os que foram reeleitos ou reafirmados por meio de referendo, estấo rotineiramente ignorando os limites constitucionais de seu poder e privando seus cidadãos de direitos e liberdades básicos." (ZAKARIA, 1997, p. 22). 
perigosa, trazendo consigo a erosão da liberdade, o abuso do poder, divisóes étnicas e, mesmo, a guerra. (ZAKARIA, 1997, p. 42-43).

Não foi o que aconteceu. $\mathrm{O}$ fenômeno ora relatado por Zakaria "não parecia concernir aos países ocidentais", constata, vinte anos depois, Karoline Postel-Vinay (2017, s/p). Enquanto "processos de eleiçôes democráticas [...] davam à luz regimes autoritários, ultrassoberanistas e prontos a reduzir cada vez mais [comme peau de chagrin] os direitos e liberdades civis dos opositores do projeto nacional" - isso na América do Sul, no norte da África, no Oriente Médio, nos Bálcâs, no sul e no sudeste asiáticos - , "[n]o coraçáo da Europa, a queda do Muro de Berlim tinha produzido uma narrativa geopolítica poderosa, e durável a despeito dos sinais precoces de fraqueza estrutural", à luz da qual "o debate público ocidental depositou a 'democracia iliberal' na prateleira dos problemas periféricos", pondera a cientista política, arrematando: "Entretanto, no curso dos anos, o que era considerado periférico, secundário, marginal tornou-se singularmente volumoso, ao ponto de transbordar as barreiras mentais que se supunham contê-lo" (POSTEL-VINAY, 2017, s/p).

Assim, em plena contramão do que desejava Zakaria, os Estados Unidos não apenas se furtaram ao protagonismo que lhes caberia em face da proliferação do "vírus do iliberalismo", como, uma vez contaminados por ele, passaram a liderar, na verdade, o que Postel-Vinay denomina "a nova Internacional planetária dos nacionalistas", dando visibilidade inédita, com isso, à pandemia global das democracias iliberais: se "faz mais de dez anos que se assiste, através de todo o planeta, a uma forte ascensão das crispaçóes soberanistas, das irrupçóes de ansiedade identitária e de xenofobia”, observa, com efeito, Postel-Vinay (2017, s/d), foi necessária a eleição de Donald Trump, seguida do Brexit, para que "fosse evocada de maneira verdadeiramente audível a escalada global de um novo nacionalismo".

Esse neonacionalismo iliberal - autoritário, soberanista, censório insurge-se, hoje, como ameaça maior à democracia no mundo, justamente porque a ameaça de dentro: "o maior perigo que a democracia iliberal apresenta", ponderava, a propósito, Zakaria (1997, p. 42), "é que ela desacreditará a democracia liberal em si mesma, lançando uma sombra sobre a governança democrática”.

Em seu compromisso fundamental em proporcionar (e resguardar) a identificação com valores democráticos, cabe à crítica, nesta conjuntura, assumir, de partida, aquela perspectiva "ambivalente e antagônica" da "nação como narração" da qual falava, há três décadas, Homi Bhabha (1990, p. 4), em vista da qual: 
A "localidade" da cultura nacional não é unificada nem unitária em relação a si mesma, nem deve ser vista simplesmente como "outro" em relação ao que está fora ou além dela. A fronteira é bifronte como Janus, e o problema do fora/dentro deve sempre ser ele próprio um processo de hibridismo, incorporando novos "povos" em relação ao corpo político, gerando outros locais de significação e, inevitavelmente, no processo político, produzindo zonas não tripuladas de antagonismo político e forças imprevisíveis para a representação política. [...] O "outro" nunca está fora ou além de nós; ele emerge forçosamente, dentro do discurso cultural, quando achamos que estamos falando o mais autóctone e intimamente "entre nós mesmos". (BHABHA, 1990, p. 4).

\section{Referências}

ARAÚJO, Nabil. Da teoria como resposta: a modernidade crítica e o (ter) lugar da teoria literária. In: CECHINEL, André (Org.). O lugar da teoria literária. Florianópolis: EdUFSC; Criciúma: Ediunesc, 2016, p. 179-215.

ARAÚJO, Nabil. Por uma pedagogia literária do "como se”. In: CECHINEL, André; SALES, Cristiano (Org.). O que significa ensinar literatura? Florianópolis: EdUFSC; Criciúma: Ediunesc, 2017,p. 31-57.

BEARDSLEY, Monroe. C. The name and nature of criticism. In: HERNADI, Paul (Ed.). What is criticism? Bloomington: Indiana University Press, 1981, p. 151-161.

BHABHA, Homi K. Introduction: narrating the nation. In: BHABHA, Homi K. (Ed.). Nation and narration. London/New York: Routledge, 1990, p. 1-7.

DERRIDA, Jacques. Force de loi: le fondement mystique de l'autorité. Paris: Galilée, 1994.

ELIOT, T. S. Tradition and individual talent [1919]. In: ELIOT, T. S. Selected prose of T. S. Eliot. Harcourt: San Diego/New York/London, 1975. p. 37-44.

FRYE, Northrop. Anatomy of Criticism: four essays. 15a ed. Princeton: Princeton University Press, 2000.

KANT, Immanuel. Kritik der Urteilskraft. Frankfurt am Main: Suhrkamp, 1974 [1790].

MOUFFE, Chantal. Deconstruction, Pragmatism and the politics of democracy. In: MOUFFE, Chantal (Org.). Deconstruction and Pragmatism. Routledge: London/ New York, 1996. p. 1-12. 
POSTEL-VINAY, Karoline. La nouvelle Internationale planétaire des nationalistes. The conversation, 2017. Disponível em: <https://theconversation.com/la-nouvelleinternationale-planetaire-des-nationalistes-73800> Acesso em: 5 de maio de 2020.

READINGS, Bill. The University in Ruins. Cambridge (MA);London: Harvard University Press, 1996.

SEVCENKO, Nicolau. A corrida para o século XXI: no loop da montanha-russa. São Paulo: Companhia das Letras, 2001.

WELLEK, René. Concepts of criticism. New Haven/London: Yale University Press, 1963.

ZAKARIA, Fareed. The rise of illiberal democracy. Foreign Affairs, v. 76, n. 6, 1997, p. 22-43.

Nabil Araújo. Doutor em Estudos Literários pela Universidade Federal de Minas Gerais (UFMG). Professor de Teoria da Literatura na graduação e na pós-graduação em Letras da Universidade do Estado do Rio de Janeiro (UERJ). Líder do grupo de pesquisa interinstitucional "Retorno à Poética: imagologia, referenciação, genericidade" (CNPq). Autor de $O$ evento comparatista: da morte da literatura comparada ao nascimento da crítica (EDUEL, 2019) e de Teoria da Literatura e História da Crítica: momentos decisivos (EDUERJ, 2020). Organizador e coorganizador de diversos volumes coletivos.

E-mail: nabil.araujo@gmail.com 